UCRL- 97938

PREPRINT

Co.NF-850504--290

\title{
INITIAL MEASUREMENTS OF BEAM BREAKUP INSTABIL ITY IN THE ADVANCED TEST ACCELERATOR
}

\author{
Y. P. Chong \\ G. J. Caporaso \\ K. W. Struve \\ This paper was prepared for submittal to \\ 1985 Particle Accelerator Conference \\ Vancouver, B.C., Canada \\ May 13-16, 1985
}

May 13, 1985

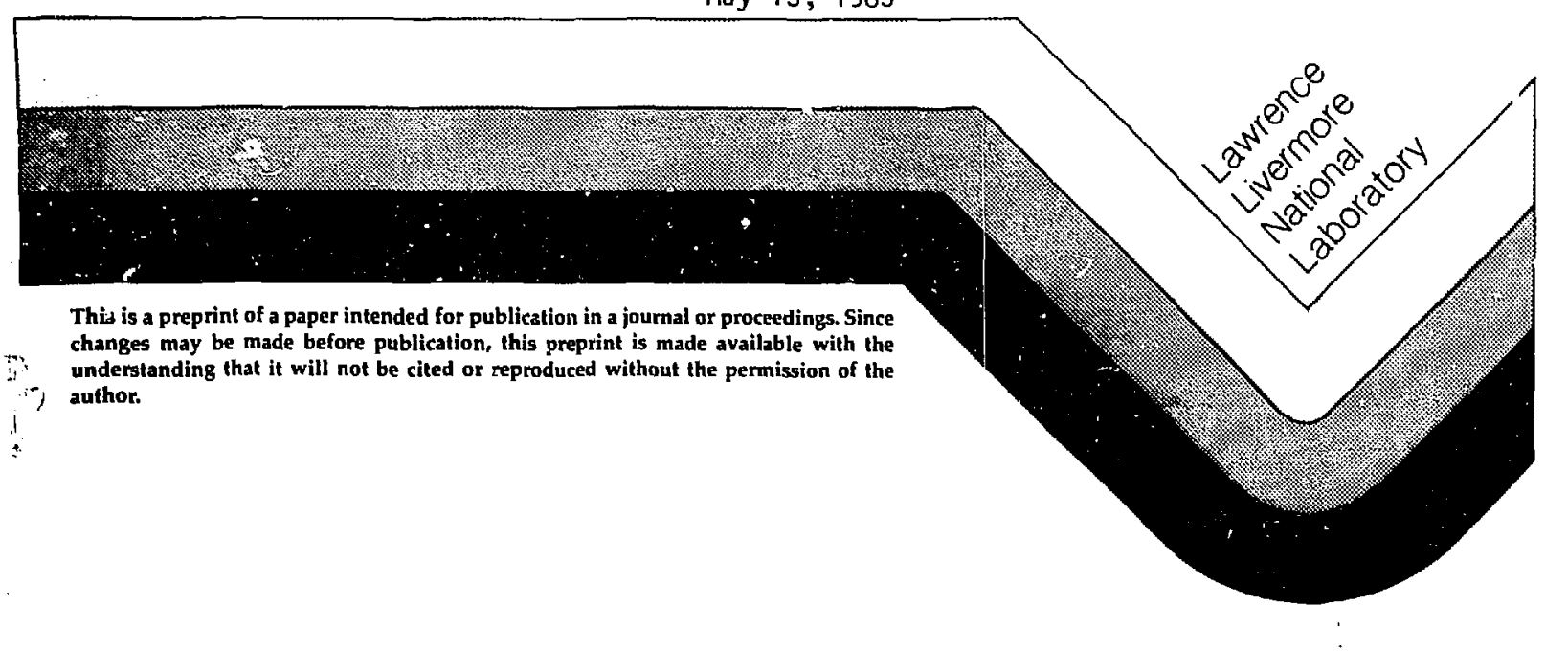


INITIAL MEASUREMENTS OF BEAM BREAKUP INSTABILITY

IN THE ADVANCED TEST ACCELERATOR*

Y. P. Chong, G. J. Caporaso, and K. W. Struve

Lawrence Livermore National Laboratory

University of California

Livermore, Califorria

May 13,1985

UCRL --91938

DE86 001583

\section{INTRODUCTION}

This paper reports the measurements of beam breakup (BBU) ${ }^{1}$ instability performed on the Advanced Test Accelerator (ATA) up to the end of February, 1984. The main objective was to produce a high current usable electron beam at the ATA output. A well-known instability is BBU which arises from the accelerator cavity modes interacting with the electron beam. The dominant mode is $\mathrm{TM}_{130}$ at a frequency of approximately $785 \mathrm{MHz}$. It couples most strongly to the beam motion and has been observed to grow in the Experimental Test Accelerator (ETA) ${ }^{2}$ which has only eight accelerator cavities. ATA has one hundred and seventy cavities and, therefore, the growth of BBU is expected to be more severe. In this paper, BBU measurements are reported for ATA with beam currents of 4 to $7 \mathrm{kA}$. Analysis showed that the growth of the instability with propagation distance was as expected for the lower currents.

\footnotetext{
*Work perforined Jointly under the auspices of the U. S. Department of Energy by LLNL under Contract $W-7405-E N G-4 B$ and for the Department of Defense under DARPA ARPA Order No. 4395 Amendment No. 31, monitored by NSWC under document number N60921-85-POkO001; and SDIO/BMD-ATC MIPR NO. W3-RPD-53-A127.
} 
However, the high-current data showed an apparent higher growth rate than expected. An explanation for this anomaly is given in terms of a "corkscrew" excitation. The injector BBU noise level for a field emission brush cathode was found to be an order of magnitude lower than for a cold plasma discharge cathode. These infector rf amplitudes agree very well with values obtained using the method of differenced $\dot{B}_{\theta}$ loops. ${ }^{3}$

\section{EXPERIMENT}

\section{A. Accelerator}

The ATA and its initial performance have been described in detail previously. ${ }^{4,5}$ In brief, it is a high current induction accelerator designed to produce electron beams of $10 \mathrm{kA}$ peak current at $50 \mathrm{MeV}$ energy and of $70 \mathrm{~ns}$ pulse duration. The $85 \mathrm{~m}$ accelerator is capable of operating at an average repetition rate of $5 \mathrm{~Hz}$ or accelerating ten pulses at $1 \mathrm{kHz}$. Presently, it consists of a $2.5 \mathrm{MeV}$ injactor and 170 accelerator cells, each providing $250 \mathrm{kV}$ acceleration. Power supplies and power conditioning equipment are housed in a buflding area above the beam tunnel. The output of each pulse power unit is delivered to an accelerator cell through two flexible, oflfilled cables. The power conditioning systems are described in more detail elsewhere. 6

B. Technique

The method employed to measure rf signals with $\dot{B}_{\theta}$ loops has been previously described. ${ }^{7}$ The growth of the instability with propagation distance through the accelerator is given by the asymptotic formula 1

$$
x \approx x_{0} \exp \left(N I \Omega Z_{1} / k_{c} I_{a}\right)
$$

where $x$ is the displacement at cavity number $N, x_{0}$ is the initial amplitude 
of the instability, $\Omega$ is the angular frequency of the mode, $Z_{\downarrow}$ is the product of $Z_{\perp} / 0$ and $Q, I_{a}$ is the Alfven current $(\sim 17,000 \mathrm{Br} \mathrm{KA})$ and $k_{c}$ is the cyclotron wave number $e B / B \gamma m c^{2}$. If the amplitude of the BBU is plotted vs cavity number on semilog axes, the slope should permit an experimental determination of $Z_{\perp}$ if the beam current and tune (B) are known. Extrapolation of the plot back to the injector (cell 10) gives a measure of the BBU noise amplitude generated in the injector.

A second method to determine the injectar rf amplitude uses differenced $\dot{B}_{\theta}$ loops. ${ }^{3}$ This is the Mirnov technique where two opposing and differenced magnetic pickup loops produce a signal proportional to the beam displacement provided the current is constant. Two orthogonal sets of opposing loops were placed at the injector output for this measurement.

The technique used to gather the data reported here involved the display of the probe signals on $1 \mathrm{GHz}$ bandwidth oscilloscopes (Tektronix 7104 with 7 A29 amplifier and 7B10 time base units). Return wall current monitors ("beam bugs") adjacent to the $\dot{B}_{\theta}$ loops provided information on pulse-to-pulse variation regarding beam current and position. A second technique consists of using a spectrum analyzer to scan the frequency spectrum on a multipulse basis. This method consumes more time and was only used occasionally.

$\dot{B}_{\theta}$ loop probes were generally located along the ATA beamline at intercell pump box stations. Each pump box has four diagnostic ports located at the top, east, bottom, and west where the probes were insertable. In practice, only the top and east ports were assigned to $\dot{B}_{\theta}$ probes. The remaining ports were taken up by vacuum hardware such as pumps, gauges, and by other diagnostics. The output stations of the infector (cell 10) and the entire 
accelerator (cell 180) held four probes each in order to gather detailed information at these important locations.

The large number of probe signal channels motivated the installation of four signal highways which could be switched to view a set of four probes simultaneously. Various combinations were posstble, such as top probes at four locations, top and east probes at two locations, or all four probes at either injector or accelerator output observations.

\section{OBSERVATIONS}

An exampie of the $\dot{B}_{\theta}$ loop signals, attenuated $100 x$, is shown in Fig. 1 for the case of $7 \mathrm{kA}$. Traces for beam current, beam charge, and centroid displacements are shown in Figs. 2 to 6 . A field emission brush cathode was used for these two cases. The BBU instability grew so rapidly that by cell 100, the oscillations had reached an amplitude of $0.3 \mathrm{~cm}$ and by cell 120 , the tail end of the pulse had eroded away. As the beam was transported through the rest of the accelerator, more charge was lost in this manner until by cell 180, half of the beam had been lost (Figs. 3,6 ). The centroid displacements show that the tail had oscillated with large enough amplitude tn be lost at the pipe wall $(6.75 \mathrm{~cm})$. A second $7 \mathrm{kA}$ case that had a faster risetime was also studied. It showed tall erosion occurring even earlier. Thus, less total charge was transported to the accelerator output.

A $5 \mathrm{kA}$ case is compared to the $7 \mathrm{kA}$ case, both having a slow risetime. Some initial loss of peak current and pulse length occurred between the injector and the first cell block. From cell 20 onwards, practically all the charge in the $5 \mathrm{kA}$ case was transported through to cell 180 . Note that at the output the maximum centroid displacements were much smaller than in the $7 \mathrm{kA}$ case. 
The peak amplit ides of the BBU oscillations were measured at various cell positions of ATA. Figure 7 shows plots of peak amplitudes vs cell numbers. The cathode for the $7 \mathrm{kA}$ plot was a field emission brush cathode, whereas the $5 \mathrm{kA}$ plot was for a cold plasma discharge cathode. The plots show that $z_{1}$ for the $5 \mathrm{kA}$ case was measured at $35 \pm 5 \Omega$, whereas the $7 \mathrm{kA}$ value was $52 \pm 5 \Omega$. A $4 \mathrm{kA}$ case (not shown here) also gave a value close to the $5 \mathrm{kA}$ case. The injector BBU oscillation amplitude was $4 \times 10^{-4} \mathrm{~cm}$ for the field emission cathode, while the amplitude for the discharge cathode was an order of magnitude higher.

\section{ANALYSIS AND DISCUSSION}

The measured value of $z_{1}$ for the 4 and $5 \mathrm{kA}$ case is very close to the predicted value of $2 B-32 \Omega$, based on ETA measurements of $Z_{\perp} / 0$ and $0 .{ }^{5}$ The ATA cavities are nearly identical to the ETA cavities, although mare mode dampening ferrite has been added to the ATA cavities resulting in lower Q's. The $Z_{\perp} / Q$ is somewhat affected by the presence of the dampening ferrite so that values determined from the ETA experiments must be corrected for the lower Q's of the ATA cavities. The cavity mode mode ${ }^{8}$ shows that the $Z_{1} / 0$ will rise slightly as the 0 of the mode is reduced. In the case uf ATA, reducing the cavity mode $Q$ down to approximately 4 results in an increase of some $11 \%$ in the value of $z_{1} / Q$ over the ETA values. Thus, the expected range of $z_{1} / Q$ for ATA is 7 to $8 \Omega$ at a $Q$ of 4 .

The method of differenced $\dot{B}$ loops gave an injector noise amplitude of $1.3 \times 10^{-4} \mathrm{~cm}$ for the brush cathode and a value ten times higher for the discharge cathode. These compare well with the present values. 
The data for $7 \mathrm{kA}$ show an anomalously high growth rate which can be qualitatively explained by a purely kinematical effect called the "corkscrew" mode. 9 If one considers the propagation of an initial transversely displaced heam pulse with a head to tall variation of energy through a solenoidal transport region, one finds that the frequency content of the transverse displacement shifts toward high frequencies as the beam propagates. This effect occurs because beam slices with slightly different energies will have slightly different cyclotion frequencies. After a large number of cyclotron orbits, the slices can be up to $180^{\circ}$ out of phase with each other. This will occur when $k_{c} z \Delta Y / \gamma \approx \pi$. For a sinusoidal variation of $r$ with time through the pulse with frequency $\omega_{0}$ the amplitude of the nth harmonic of $\omega_{0}$ is $2 x_{0}{ }_{n}\left(k_{c} z \Delta y / \gamma\right)$ where $x_{0}$ is the initial transverse displacement of the beam and $J_{n}$ is the usual Bessel function of order $n$. Thus, even a relatively low frequency energy modulation has a frequency component at the BBU frequency which will eventually attain amplitude $-2 x_{0}$. In ATA, this offset was typically a few $\mathrm{mm}$.

The source of the energy variation in ATA is the nearly critically damped circuit response of the accelerator cavity-pulse power drive system. ${ }^{9}$ The beam current is an excitation source for this circuit which has a resonant frequency of $\approx 50 \mathrm{MHz}$. The magnitude of the energy vartation is proportional to the peak ceam current and can approach $20 \%$ near the head of the beam pulse. Thus $\Delta \gamma$ increases with beam current and the 16th harmonic $(\approx 800 \mathrm{MHz})$ grows more rapidly in axial position. If the increase in this harmonic due to the corkscrew is more rapid than the normal BBu growth, then the BBu growth will appear anomalously high at higher beam currents. 
Techniques that may reduce the BBU instability level include (a) minimizing the injector noise, (b) a slower risetime, (c) a faster ramp-up of $B_{2}$ near the injector, (d) a low pressure IFR in the accelerator (spoiled vacuum) and (e) laser guiding. of these approaches, laser guiding has been found to be effective and is currently employed at ATA.

\section{CONCLUSIONS}

The growth of the BBU instability for low currents on ATA is about as expected on the basis of theory and previous experience with ETA operation. The "corkscrew" excitation mechanism can qualitatively account for the anomalously high growth rate of BBU for the higher current. The injector noise level was ten times lower for the field emission brush cathode than the cold plasma discharge cathode. The obtained values agree very well with direct measurements of the injector of amplitudes using the method of differenced $\dot{B}_{\theta}$ loops. 


\section{REFERENCES}

1. V. K. Neil, L. S. Hall, R. K. Cooper, "Further Theoretical Studies of the Beam Breakup Instability," Particle Accelerators, Vol. 9, pp. 213-221, 1979.

2. R. E. Hester et a 1., "The Experimental Test Accelerator (ETA), "IEEE Trans. Nucl. Sct. Vol. NS-26, No. 3, pp. 4180-4182, June 1979.

3. K. W. Struve, "Differenced $B_{\theta}$ Loops for Measuring Low Leve 1 Excitations of the Beam Breakup Instability in Linear Accelerators, "to be published.

4. D. S. Prono, et al., "Survey of Initial Experiments on ATA Beam Dynamics," Lawrence Livermore National Laboratory, Livermore, CA, UCID-20264.

5. R. J. Briggs, "High Current Electron Linacs (Advanced Test Accelerator/ Experimental Test Accelerator)," in Proceedings of the LINAC ' 84 Conference in Darmstadt, West Germany, June 7-11, 1984.

6. L. Reginato, "The Advanced Test Accelérutor (ATA), 50 MeV, Induction Linac," IEEE Trans. Nucl. Sci. Vol. NS-30, No. 4, pp. 2970-2974, August 1983.

7. G. J. Caporaso and K. W. Struve, "Experimental Studies of the Beam Breakup Mode on ETA: Comparison with Theory," Lawrence Livermore National Laboratory, Livermore, CA, UCID-19402.

8. G. J. Caporaso, A. G. Cole, and K. W. Struve, IEEE Trans. Nucl. Sci., Vol. NS-30, pp. 2507-2509, 1983.

9. G. J. Caporaso, et a 1., "Beam Dynamics in the Advanced Test Acceleratur (ATA)," Proc. 5th Int 1. Conf. High-Power Particle Beams, San Francisco, CA, September 12-14, 1983, pp. 427-432. 


\section{FIGURE CAPTIONS}

Fig. 1. $\dot{B}_{\theta}$ loop signals showing growth of beam breakup oscillations for a 7 KA tune.

Fig. 2. Beam transport for 7 kA vs 5 kA, slow risetime with brush cathode peak current comparison.

Fig. 3. Charge transport comparison for $7 \mathrm{kA}$ vs $5 \mathrm{kA}$.

Fig. 4. Current traces showing slow risetime and small centroid displacements at injector output.

Fig. 5. Beam breakup oscillations eroding tall of beam for 7 KA case.

Fig. 6. Transport of full beam for $5 \mathrm{kA}$ case as compared to tail erosion for $7 \mathrm{kA}$ case.

Fig. 7. Growth of BBU in $7 \times A$ case (dotted line) is anomalously higher than in $5 \mathrm{kA}$ case (solid line). Injector $\mathrm{rf}$ amplitude (cel1 10) is ten times higher for brush cathode than for discharge cathode.

\section{DISCLAIMER}

This report was prepared as an account of work sponsored by an agency of the United States Government. Neither the United States Government nor any agency thercof, nor any of their employees, makes any warranty, express or implied, or assumes any legal liability or responsibility for the accuracy, completeness, or usefulness of any information, apparatus, product, or process disclosed, or represents that its use would not infringe privately owned rights. Reference herein to any specific commercial product, process, or service by trade name, trademark, manufaciurer, or otherwise does not necessarily constitute or imply its endorsement, recommendation, or favoring by the United States Government or any agency thereof. The views and opinions of authors expressed herein do not necessarily state or reflect those of the United States Government or any agency thereof.

$Y P C / j c: 0078 c$ 


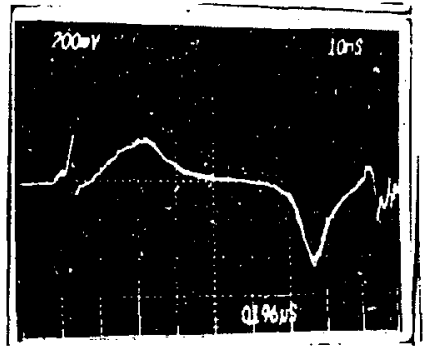

After injector

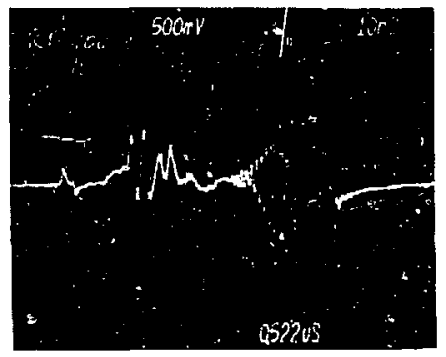

After cell 100

$10 \mathrm{~ns} / \mathrm{div}$

Figure 1
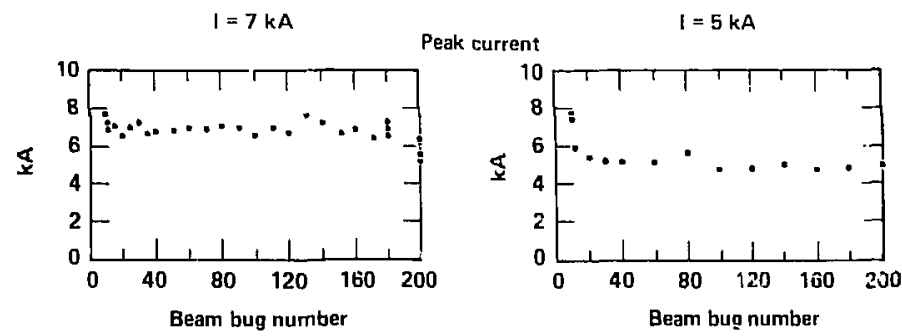

Figure 2 

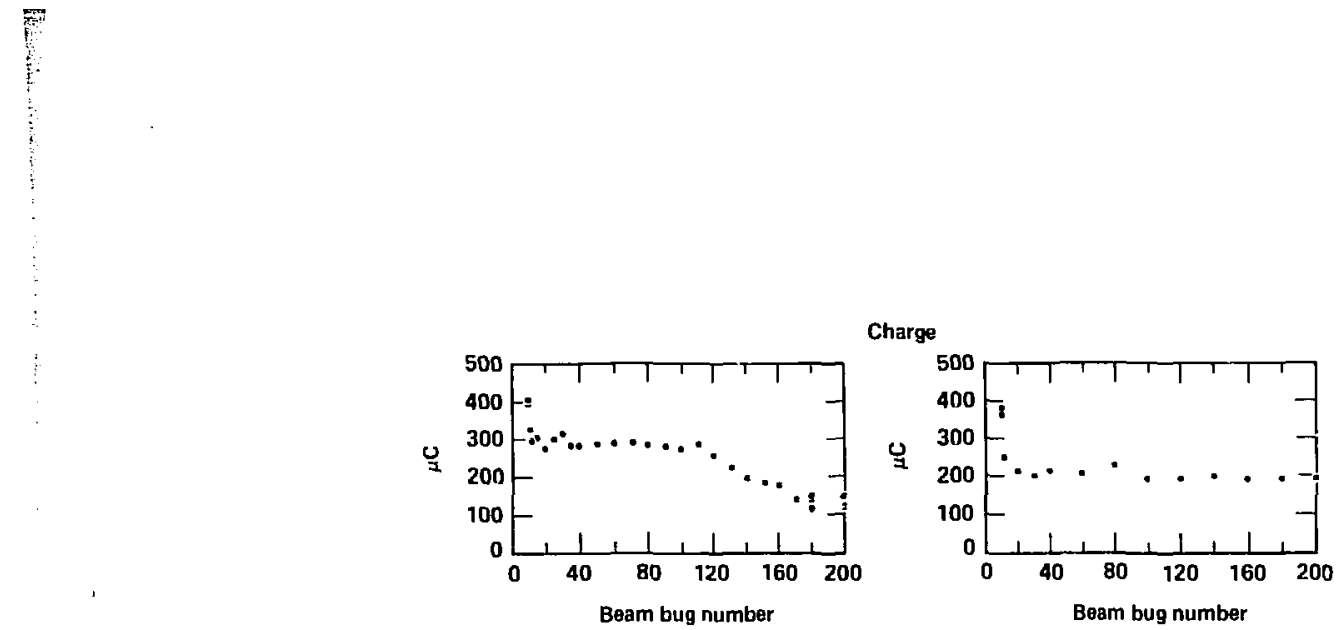

Figure 3

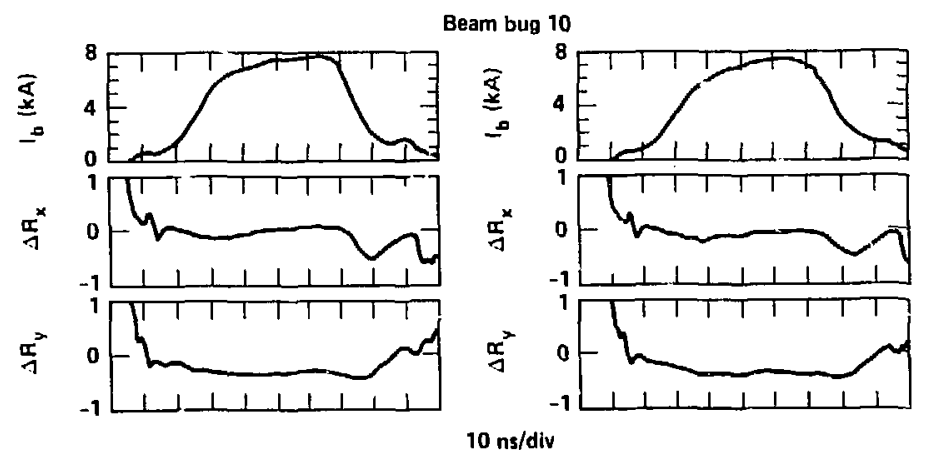

Figure 4 


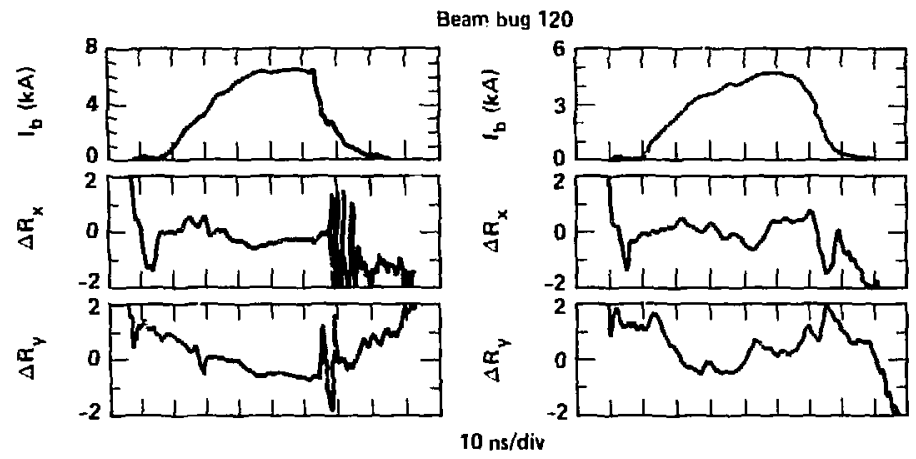

Figure 5

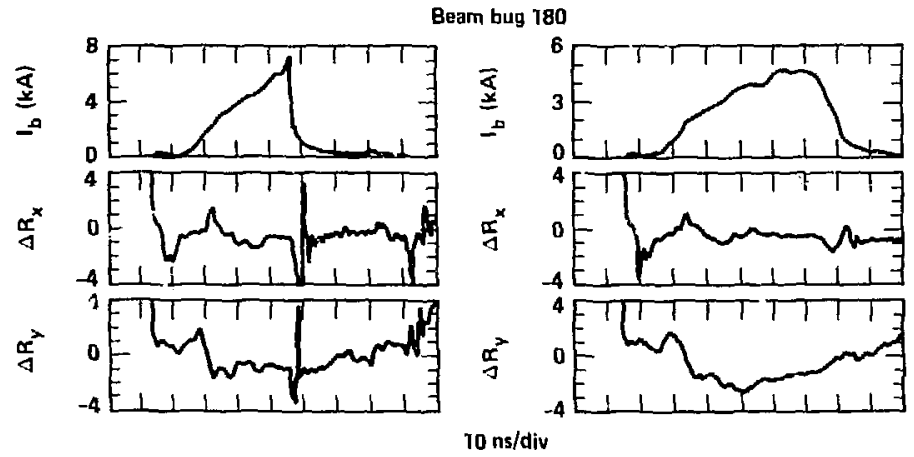

Figure 6 


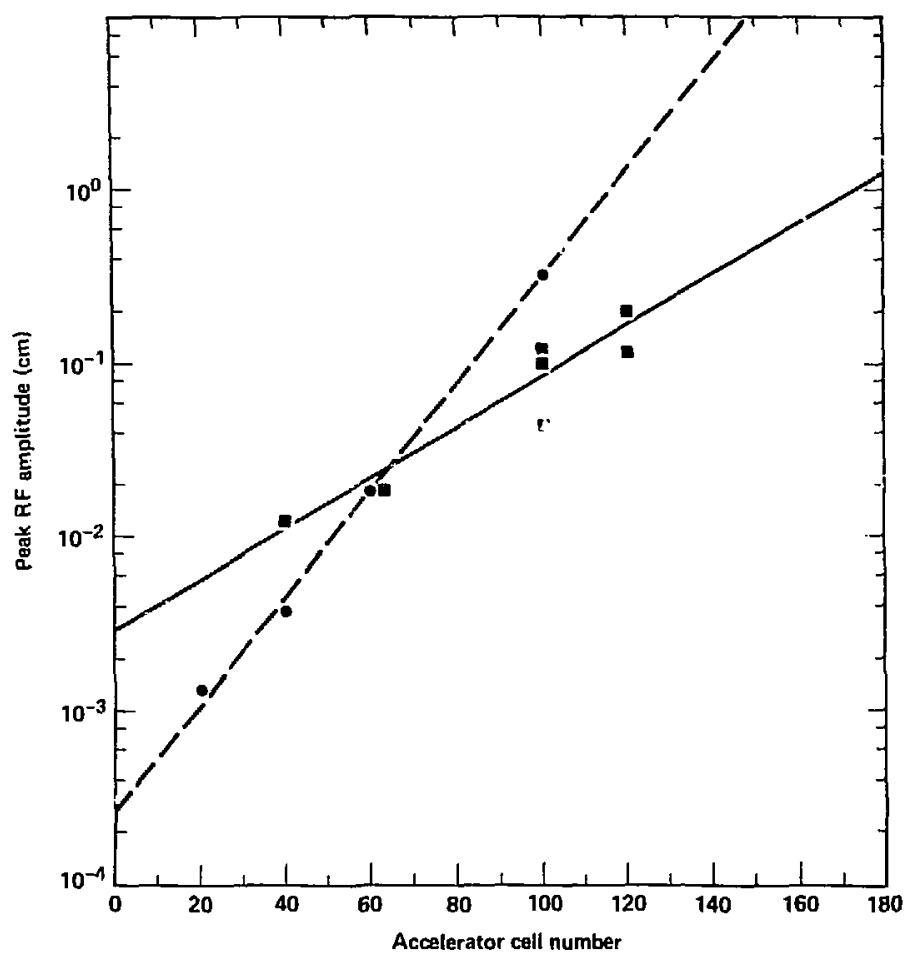

Figure 7 